\title{
For Value or for Worth? Part 1: Speaking Syllogistic Attractors of Appropriations in a Thought-Action-Mood-Space
}

\author{
Gottfried Reinhold Sebastian Treviranus \\ BipoSuisse, Independent Research, Vereinsweg 11, CH-3012 Berne, Switzerland \\ *Corresponding Author: biposuisse@bluewin.ch
}

Copyright $\bigcirc 2017$ by authors, all rights reserved. Authors agree that this article remains permanently open access under the terms of the Creative Commons Attribution License 4.0 International License

\begin{abstract}
Epistemiology requires trans-disciplinary logics for convergence. As a fundamental of the brain, this essay's hypotheses revisit the Goethean alternation between "Newtonian" symbolic frontal 4-dimensional (Halford) processing ("4D-Thought"), and parietal intellectual intuition (" $5 D+$-Action") interpreting high-dimensional articulated motor-chains (Rizzolatti). SuchS a classical temperamental and anxio-affective triad of dimensions ("Thought", "Action", "Mood") constitutes the "dyn4-TAM-cube"-model, reflecting segregated cortico-striato-thalamo-cortical circuits. "dyn4-TAM-cube" harbors cycling "Appropriation Waves" transiting from private "4DThought" to public "5+Action" and back. At "Intention" to act predictive Pavlovian cues, possibly tempting by discounted effort, incentivate, and at "Perception" Skinnerian learning relates "worth"-related outcome to effortful appropriations (see part2). Sorrentino's prime motivating "orientation" when facing the unexplained unknown dictates this balance. Thereby uncertainty- versus certainty-oriented actors ("UOs" vs. "COs") differ inversely and interactively in "Mood": whilst reducing future effortful "known unknowns" by models or by doing. Rats show a arguably homologous sign- versus goal-tracking dimension, as controlled by the thalamic paraventricular nuclei, where mast cells might mediate the reversal in orientation observed in depression. Natural language terms denoting the 8 corners and 56 intercalated processes link "dyn4-TAM-cube" to psychotherapy and to thalamic (neuro-)linguistics, as "dyn4-TAM-cube" via syllogisms of a doubled Square of Oppositions maps language to logical terms, which speak through the former.
\end{abstract}

Keywords Square of Oppositions, (Un-)certainty Orientation, Sign-tracker, Prediction Error,

Neuro-economics, Neuro-linguistics,

Cortico-subcortical-thalamo-cortical circuits, Mast Cell

\section{Introduction and Methods}

Convergence [1] requires trans-disciplinary logically transposable frameworks for behavioral sciences.

\subsection{A Triadic Model for Appropriating Behavior}

This essay accordingly and boldly explores aspects of the mind through the, logically structured and bio-neurolinguistically expanded pendulum model. Its integration of thought, action, and mood stems from the French Enlightenment and is related to temperament and bipolar disorders [2].

It thereby revisits the Goethean [3] fundamental alternation between two kinds of thinking:

- a) the "Newtonian" symbolic frontal processing, limited to 4 dimensions $[4,5,6]$, here called " $4 D$-Thought" or " $4 D \mathbf{T} \sim$ " (see abbreviation codes ${ }^{\mathrm{i}}$ ), and

- b) the aesthetic intellectually intuitive "Anschauung" [7] mastering the meaning of high-dimensional articulated motor-chains mostly in the parietal lobe [8], here called " $5+D$-Action" or " $5+\mathbf{A} \sim$ "(Figure 1).

This enquiry uses "dyn4-TAM-cube", an own spatial classical thought-action-mood-model, which contains its own critique. Herein e.g. much "T $\sim$ ", little "A $\sim$ ", and positive "M $\sim$ " results in the state of "Interest-T $\sim / \mathbf{a} \sim / M \sim$ " at one of eight corners of a cube. Their non-clinical names and codes are: Need-t $\sim / \mathbf{a} \sim / \mathrm{m} \sim$ (with mutants Worry- $\mathrm{T} \sim \mathrm{a} \sim / \mathrm{m} \sim$, Fear-t $\sim / \mathrm{A} \sim / \mathrm{m} \sim$, and Bliss-t $\sim \mathrm{a} \sim / \mathrm{M} \sim)$ and Pursuit-T $\sim \mathrm{A} \sim / \mathrm{M} \sim$ (with mutants Joy-t $\sim \mathrm{A} \sim / \mathrm{M} \sim$, Despair-T $\sim \mathrm{A} \sim / \mathrm{m} \sim$, and Interest-T $\sim \mathrm{a} \sim \mathrm{M} \sim$ ).

Each corner sends seven transitional processes towards peers, corresponding to 8 plus 56 natural language terms (Figure 3) [2, Table 1].

The cube, following "Fig. 228" illustrating bipolar mixed states [9], also contains an inscribed simple harmonic 
oscillator (SHO) reflecting the momentary or averaged "Appropriation Wave" (AW). This SHO, with bound frequencies and amplitudes, represents $[10,11]$ the engine of appropriation, related to oscillating indirect and direct cortico-striatal pathways [12].

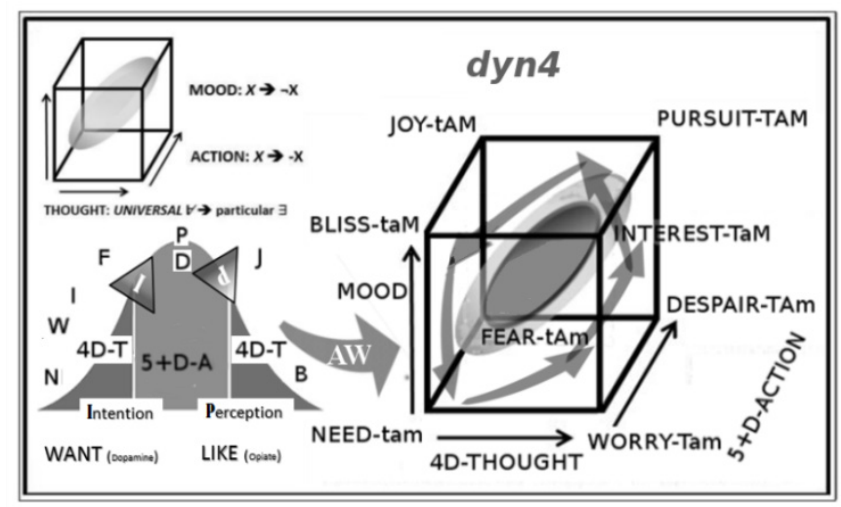

Figure 1. The dyn4-TAM-cube's classical dimensions interpreted as logical operations: $4 D \mathbf{T} \sim$ from universals $\forall$ creates a set of particulars $\exists$, $5+\mathbf{A} \sim$ "either/or" $\Delta$, and MOOD sublation $(x \rightarrow \neg x)$ The dichotomic permutations at each corner declare spoken psychological stances (N,W, I, F, P, D, J, B) which attract or repel appropriative cycles (AWs, lower left). AWs swap from $4 D \mathbf{T} \sim$ to $5+\mathbf{A} \sim$ at Intention and back to $4 D \mathbf{T} \sim$ at Perceptions.

The cube's dichotomous permutations $(\mathrm{T} \sim / \mathrm{t} \sim, \mathrm{A} \sim / \mathrm{a} \sim$, $\mathrm{M} \sim / \mathrm{m} \sim$ ) attract or repel the hereby shaped AW (Figure 1), as do framing paths to and fro "Need-Pursuit-(Outcome)" along 2 to 14 corners.

Predecessors for triadic and/or sequential "affective" models include: Jean Fernel $\left(16^{\text {th }} \mathrm{c}.\right)$; Jean-Pierre Falret $\left(19^{\text {th }} \mathrm{c}\right.$ ); Charles Sherrington, Wilhelm Weygandt, Emil Kraepelin, Hans Lungwitz $\left(19^{\text {th }} / 20^{\text {th }}\right.$ c. $)$; Silvan S. Tomkins, Ullrich Supprian $\left(20^{\text {th }} / 21^{\text {th }}\right.$ c. $)$; Richard Depue, Sydney Axinn, Richard M. Sorrentino, and Joaquin Fuster.

\subsection{The Syllogistic Formalization of Approach}

Furthermore a formalization of such relations in approach can be achieved through an Aristotelian use of syllogisms adapted from Sydney Axinn [13], who to this end doubled the "square of oppositions" (SquOpp). Similarly one square by doubling achieves a dimension of " $5+D \mathbf{A}$ " which generates a simple distance in approach, which in in dyn 4 is defined by "either $x$ or $-x$ ". The simple modeling via " $4 D$-T" instead in $d y n 4$ is conceived as the attributive transition from "true for all" $(\forall)$ to "true for at least one" $(\exists)$ during the foundation of a set. Finally positive $\mathrm{M} \sim$ in $d y n 4$ results from a sublation (negation) of a state of need " $\mathrm{x}$ " $(\neg \mathrm{x})$.

Hereby, by negations, on each face a graduation of applicable truth results: For all $(\forall)$, NOT for all $(\neg \forall)$, for some $(\exists)$, "NOT even for some, for none" $(\neg \exists)$ (Figure 2).

"Not for all" in this is assumed to be understood as more comprehensive than "for some." The thus generated triadic logical structure evokes the natural language terms at the corners and of the processes which swap these. Hereby syllogistic neuro-linguistical operations are convergently predicted, which emerge from studies of the thalamus.

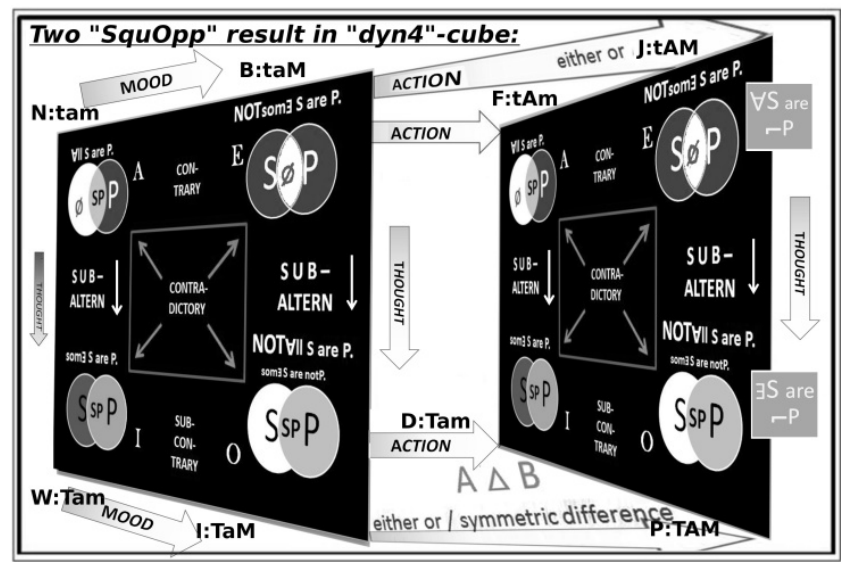

Figure 2. Square of Opposition (SquOpp) about Subjects \& Predicates maps on Mood and Thought. It graduates the either-or of approaching Action generated by its doubling. A tilted dyn4-TAM-cube results with permutations: Need-t $\sim / \mathbf{a} \sim / \mathrm{m} \sim(\mathbf{N}: \operatorname{tam})$ to Pursuit-T $/ \mathrm{A} \sim / \mathrm{M} \sim(\mathbf{P}: \mathbf{T A M})$.

\subsection{Variably Resented Explaining Efforts}

Beyond encoding for growth or destruction "Mood/M " modulates the "T $\sim / \mathbf{A} \sim$ "-alternation in a way increasing collective fitness through inter-individual variation e.g. in foraging. During symbolic modeling for future physical effort-reduction choleric "soldiers" [14] worsen their mood as if they resented cognitive effort, while that of sanguinic "philosophers" improves - unless depression doesn't reverse these relations.

Such temperamental differences in the motivational attitude towards unexplained "(un)knowns" have been localized between the dimensional extremes of "Un-"and -Certainty-Orientation" by Richard M. Sorrentino $[15,16]$. He qualified this as the decisive trait-like motivator in human appropriative approach, only subordinate to the valence of "Mood". In high spirits this contrast is increased, but lossminimizing depression may invert this cognitive style. In terms of dyn4 thus "Mood" along AWs interactively participates in the balance of low- to high-dimensional cognitive processing.

While cognitive effort [17] and incentivization seem central to this orientation, their relation is complicated by the role of con- and dissonance and the "loyalty" towards beliefs held in modeling modules MBL [18].

\subsection{Moody Learning at Dimensional Transition Points}

Symbolic "4DThought" $(\mathbf{T} \sim)$ and intuitive " $5+D$ Action" $(5+D \mathbf{A} \sim)$ thus alternate [3] by crossing the "affordant" [19] interfaces "Perception" $(\mathrm{A} \rightarrow \mathrm{T})$ and "Intention" $(\mathrm{T} \rightarrow \mathrm{A})$. To modulate this cognitive alternation is a little recognized key function of "Mood". 
Importantly through repeated appropriations learned contents are fed from both $\mathbf{T} \sim / \mathbf{A} \sim$-interfaces of $\mathbf{A W}$ s into $\mathbf{T} \sim$ about:

- a) Pavlovian cues, which besides being predictive of specific reward, maybe become incentive as predictors of tempting abstract discount of expected effort at "Intention" $(\mathbf{I}\{\mathrm{T} \rightarrow \mathrm{A}\})$ as one can suspect from its utility at the onset of an $\mathbf{A W}$, and

- b) Skinnerian instrumental appropriative movements for complex needs at "Perception" $(\mathbf{P}\{\mathrm{A} \rightarrow \mathrm{T}\})$.

In fact "valuation", $(\mathbf{P}\{\mathrm{A} \rightarrow \mathrm{T}\}$ in the $\mathrm{OFC} / \mathrm{vmPFC}$ and "selection", $\mathbf{T} \sim$ in dlPFC (orbito-, ventromedial, and dorsolateral prefrontal cortex), are dissociable [20].

While sanguinics indulge in economic 4DT-modeling of "value", tempted by expected spared effort for future moves appropriating "worth" (itself processed in 5+ dimensions), cholerics prefer to rely on engrained complex instrumental habits.

\subsection{Neuro-Economy of the Unknown: Uncertain Signs vs. Certain Goals?}

Through the purported homology of rodent "sign-tracking" [21] with human "UO-vs.-CO"-behavior this framework can mobilize support from neuroscience, while it generates a critique of the "collapsing" use of Bayesian "prediction errors" in neuro-economics.

\subsection{Do Thalamic Mast Cells Provide The Moody Switch?}

The thalamic paraventricular nuclei (PVT), beyond their key role as bio-economical subcortical hubs [21,22,23], provide a central switch for "orientation" towards cues. They show chemical connectivity with the shell of the Nucleus accumbens (Nac) in "Sign-tracker" (ST) rats with UO-like behavior and with e.g. prelimbic PFC CO-like "Goal-trackers" (GTs) [24,25]. Exitotoxic lesioning of the PVT in training slowly increases the former UO-like behavior in all, while applied later it increases UO-like, whereas it decreases CO-like behavior, for the acquisition of which an intact PVT was needed [26].

The orientation of humans towards un-/certainty becomes reversed when minimizing losses as in depression [15]. This might occur through stimulation from peripherally imprinted mast cells reaching the PVT along the outside of posterior arteries, where the Cortico-striato-thalamo-cortical circuits (CSTCs) converge. In fact only cues which are incentive, i.e. especially in ST-rats, engage CSTCs [22], possibly to process a discount in specific effort expected for appropriation. In CO-like GT-rats this therefore doesn't seem to occur. The lack of sexual dimorphism in ST [27] in the realm of affective disorders fits with bipolar depression, but not with other disorders.

\section{Balancing Complexity in Approach}

Appropriative approach requires varying balances between low- and high-dimensional processing.

\section{1. dyn4-TAM Appears as neuro-biologically hard-wired}

Unlike anticipated reward or final outcome anticipated effort per se, independently of valence, lights up: in the ACC, supplementary motor area (SMA), and dorsal putamen, while the ventral putamen appears more active with RPEs whilst perceiving unexpectedly better than worse outcomes, but less so after strong effort [36]. Cued temptation also correlates with activity in the mesolimbic output structure ventral putamen [37]. In primates and rats [38] the ventral striatum and ACC seem central to effort-discounting, while in fMRI [39] the posterior OFC and insula seemingly are ignited by anticipated worth processed in $5+D \mathbf{A} \sim$. Cue-driven transient activity instead activates BG and dIPFC (representing 4DT $\sim$ ) bilaterally [40], which possibly relates to processing less anticipated into 1-dimensional economies themselves "unrelated to the performance of the action" [41].

Genetico-affective biaxiality between $4 D \mathbf{T} \sim$ and $5+D \mathbf{A} \sim$ [42] can be reinforced by an overlay [10] with phylogenetic biaxiality. In the amygdala e.g. subjective goals are set [43] and within this "what"-planning amygdalo-dorsal developmental stream [44] more receptor-driven modules for 4DT about "what" could operate. These alternate genetico-affectively with the brain's more channel-driven modules for 5+DA within the "where"-processing hippocampo-ventral stream, supported respectively by the anterior and medio-dorsal thalamic nuclei [45].

Within the evolving concepts of CSTCs [46,47] the thalamus [48] harbors the incompletely segregated more-from-than-to final relays back to the cortex whilst interacting with partners also in reward circuitry. In fact dopaminergic projections not only to the ventral, but also non-segregated nigro-striatal mood-regulating ones to the dorsal striatum pertaining to the CSTCs were found. These also fire proportionally to approach or aversively little, whilst not encoding aversion per se [49]. Furthermore blocking DA2-receptors diminishes the "willingness to engage" in effort [50]. Therefore a decrease in expected effort both for approach or retreat could in part be encoded by DA (see part 2), while stimulation near the substantia nigra pars compacta results in instrumental learning [48]. Effort itself is emerging as a result of specifically patterned glutamatergic input on midbrain DA-neurons [51].

\subsection{Symbolic $4 D$-Thought graduates the Vague Future}

Ideas have often used triadic concepts, which including time, put 4-dimensional strains on our often conscious operative "symbol-handling" resources, which cannot deal with more independent processes [4,5,6]. This low-complexity faculty " $4 D$-Thought" in $d y n 4$ represents agentic density of thoughts commanding future actions - as 
required e.g. by syllogistic relational processing [28].

As " $4 D \mathbf{T} \sim$ " generates the passage from universals $(\forall)$ to meaningful particulars $(\exists)$ and their negation within the SquOpp. It provides a 4-step graduation of applicable truth: For all $(\forall)$, NOT for all $(\neg \forall)$, for some $(\exists)$, "NOT even for some, for none" $(\neg \exists)$, which the rigid "either/or" in spatial approach (and its processing by $5+D \mathbf{A}$ ) lacks and therefore needs for wish-fullfilling sublation into positive Mood (Figures 1, 2).

\subsection{Intuitive 5+D-Action Appropriates with Precision}

"5+Action" refers to the intuitive, particularly human, parietal [29] high-dimensional cognitive processing required to understand $[8,30]$ articulated body-chains through efference copies [31].

Also aesthetics, dealing with intellectual intuition in "free", non-"burdensome" non-craft, non-"mercenary art" [32], essentially involves kinetic complexity [33,34,35].

By switching one face of Sydney Axinn's [13] relationally doubled square of (syllogistical) oppositions (SquOpp) a spatial logical structure is achieved which can be mapped to the dyn4 (Figure 2).

\section{Triadic Signatures of Approach}

The AWs inscribed in in dyn4-TAM-cube are full triadic signatures of affective traits and seemingly hardwired [52] within the three "temperamental" CSTCs [53].

These have been mapped [54,55] through lesions [56,57]: disorganized "Thought" to the dorso-lateral prefrontal cortex (dIPFC), non-cognitive abulia, muting "Action", to the anterior cingulate cortex (ACC), and anhedonia or instinct- and "Mood"-driven impulsivity to the orbitofrontal PFC (OFC). The OFC links informative sensations to outcomes, which fits with the definition of emotions as "analogue amplifiers" [58], and resonates with the amygdala, which is more flexible in learning aversive versus attractive contingencies [85] than the OFC.

This triadic structure can also be read from the insular cortex [59].

\section{Thalamic Appropriative Language?}

Since the above dyn4-transitions generate 56 natural language terms (Figure 3) through dichotomous expression of triple permutations of particulars, approach, and successful appropriative sublation [60], these not only "speak through syllogistic states", but also predict putative neuro-linguistic operations emerging from convergent research [61].

Coding true as bold upper and false as lower case letters, the corner "Despair-T $\sim \mathrm{A} \sim / \mathrm{m} \sim$ " e.g. states: "Something, (4DT $\sim)$, can be approached, $(5+D \mathbf{A} \sim)$, but not sublated, $(\mathrm{m} \sim)$ !" or "Joy-t $\sim / \mathrm{A} \sim / \mathrm{M} \sim$ : "All, $(\mathrm{t} \sim)$, is approached, $(\mathbf{A} \sim)$, and sublated, $(\mathbf{M} \sim)$ !". Finally "Rescue" $(\mathrm{D} \rightarrow \mathrm{J})$ and "Frenzy" $(\mathrm{J} \rightarrow \mathrm{D})$ denote the transitions between these two.

\subsection{The Thalamus Emerges as Syllogistic Speaker}

The linguistic thalamus in fact responds to complex permutations [62], transmits cortico-cortically [63], sharpens the focus through the CSTCs, joins cognitive and motor processing [64], chooses words [65] or syntax [66] intending minimized efforts [67]. Direct tracts connect Broca's region to the anterior thalamus [68]. The thalamus reciprocally [69] engages cortical modules, and e.g. diverges widely to cortical layer 1 after intralaminar thalamic nucleus gating [70].

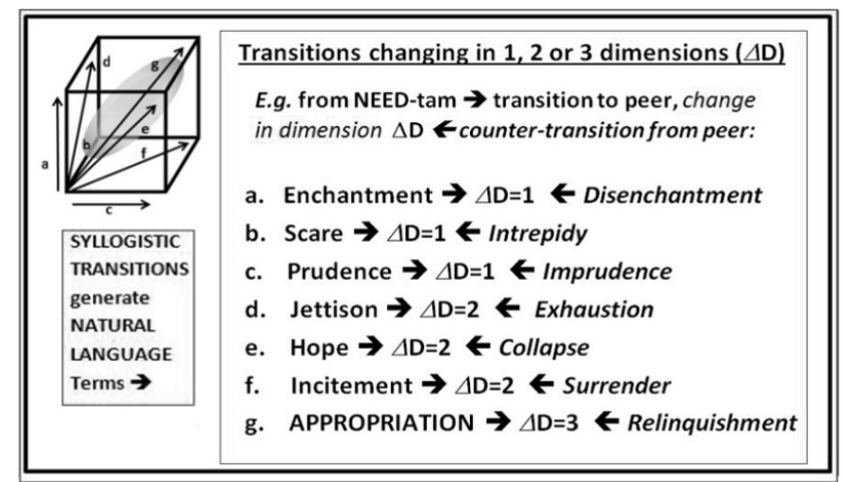

Figure 3. Seven one-step transitions from each syllogistic stance involve up to four nodes (or swaps over 1 to 3 dimensions) generating 56 psychologically meaningful processes and counter-processes. These - e.g. starting from "depressive" NEED - generate psychological natural language terms.

\section{The Tempting Value of Less Effort}

The recurrent AWs of dyn 4 require an early computation, as related to the ventral striatum [71], of an opportunity as ratio of specific reward-worth to a priceable proportion of own expendable maximal effort. Whilst processing in the ventral striatum occurs early before intention, its scope from outcome seems provided by OFC [72,73]. Specific opportunities therefore will be perceived as attached to, thus conditioned and fetishized, cues, helping to overcome effort through the signaling of opportune expenditure, but not through resulting rewards - or punishments [74] - per se. STs show instrumental, but not Pavlovian extinction [75]. When frustration ceases, "taxic" cue-effects proportional to DA show exhaustion [76] and STs in fact fail to suppress CR after outcome devaluation [77] or even when punished for approach [78], arguably because the cue-associated relief of effort-related suffering becomes even more attractive in the context of additional suffering, like the one caused by periods of non-reward, to which they show a sluggish extinction of response [34].

\section{Uncertainty-oriented Sign-tracking of Discounts?}

Many insights into appropriative Perceptions (" $\mathrm{A} \rightarrow \mathrm{T}$ ") of external cues, driving the "wanting" of dopaminergic 
incentive appetite, and of the internal opioidergic consummatory pleasure of "liking" stem from the Ann Kelley lab [21,79]. Their sign-tracking (STs) rats [80,81] showed the peculiar behavior, not to explore the feeding magazine as much as goal-trackers (GTs), but to focus on more distant cues only vaguely and transiently associated with the "conditioning" chew - even when actions on the cue-contingent lever would cancel reward [80].

High performance of STs on a "joy-stick-task" with "action discovery" $[82,83]$ would not prove their homology with UOs [15] since STs display a co-bred non-novelty [82] attraction for cues. Neurons for the latter "cue-riosity" in the OFC, before decision (within 4DT $\sim$ ), fire "orthogonally" [84] i.e. in disregard of decisional context (within $5+\mathbf{A} \sim$ ). Processing aversive circumstances, which considers effort too, shows overlap with that of rewards [85].

Part 2 of this essay explores consequences for some of the current neuro-economical and neuro-biological debates.

Table 1. Synopsis of natural language terms denoting transitions in the dyn4-TAM-cube.

\begin{tabular}{|c|c|c|c|c|c|c|c|c|}
\hline & Bliss & Joy & Pursuit & Interest & Need & Fear & Despair & Worry \\
\hline Bliss & $\underset{\text { from }}{\rightarrow}$ & Exaltation & $\begin{array}{c}\text { Prosely- } \\
\text { tism }\end{array}$ & $\begin{array}{c}\text { Committ- } \\
\text { ment }\end{array}$ & $\begin{array}{c}\text { Disenchant } \\
\text { - ment }\end{array}$ & Startle & Fanatism & Nostalgia \\
\hline Joy & Hypostasis & $\rightarrow$ to & Dedication & Flow & Exhaustion & Arrest & Frenzy & Doubt \\
\hline Pursuit & Epiphany & Neglect & $\rightarrow$ from & $\begin{array}{c}\text { Scatti- } \\
\text { ness }\end{array}$ & $\begin{array}{c}\text { Relinquish } \\
\text { - ment }\end{array}$ & Shock & Defiance & Damnation \\
\hline Interest & $\begin{array}{l}\text { Stultifi- } \\
\text { cation }\end{array}$ & Jubilation & $\begin{array}{l}\text { Applica- } \\
\text { tion }\end{array}$ & $\underset{\text { from }}{\rightarrow \text { to }}$ & Sobering & Awe & Aberrancy & $\begin{array}{c}\text { Insolva- } \\
\text { bility }\end{array}$ \\
\hline Need & $\begin{array}{c}\begin{array}{c}\text { Enchant- } \\
\text { ment }\end{array} \\
\end{array}$ & Jettison & $\begin{array}{l}\text { APPRO- } \\
\text { PRIATION }\end{array}$ & Reflection & $\rightarrow_{\text {from }}$ to & Scare & $\begin{array}{c}\begin{array}{c}\text { Incense- } \\
\text { ment }\end{array} \\
\end{array}$ & Prudence \\
\hline Fear & $\begin{array}{l}\text { Confi- } \\
\text { dence }\end{array}$ & Escape & Salvation & $\begin{array}{l}\text { Cogni- } \\
\text { zance }\end{array}$ & Freezing & $\underset{\text { from }}{\rightarrow}$ & \begin{tabular}{|c|}
$\begin{array}{c}\text { Entangle- } \\
\text { ment }\end{array}$ \\
\end{tabular} & Attrition \\
\hline Despa & $\begin{array}{c}\begin{array}{c}\text { Valoriza- } \\
\text { tion }\end{array} \\
\end{array}$ & Rescue & $\begin{array}{l}\text { Redemp- } \\
\text { tion }\end{array}$ & Hope & $\begin{array}{c}\begin{array}{c}\text { Surren- } \\
\text { der }\end{array} \\
\end{array}$ & $\begin{array}{c}\begin{array}{c}\text { Self- } \\
\text { muting }\end{array} \\
\end{array}$ & $\underset{\text { from }}{\text { to }}$ & Brooding \\
\hline Worry & Providence & Relief & $\begin{array}{l}\text { Reme- } \\
\text { diation }\end{array}$ & ability & $\begin{array}{l}\text { Impru- } \\
\text { dence }\end{array}$ & Enactment & Vengeance & $\underset{\text { from }}{\rightarrow}$ \\
\hline
\end{tabular}

\section{REFERENCES}

[1] H. A. Eyre, H. Lavretsky, M. Forbes, C. Raji, G. Small, P. McGorry, B. T. Baune, C. Reynolds. Convergence Science Arrives: How Does It Relate to Psychiatry? Academic Psychiatry 41(1), 91-99, 2017. doi:10.1007/s40596-016-0496-0.

[2] F.K. Goodwin, K. R. Jamison, in Chp. 2. Clinical Description. In: F. K. Goodwin,, K. R. Jamison. Manic-Depressive Illness: Bipolar Disorders and Recurrent Depression, (Table 2-13, pp. $75-76)$, 2nd Edition. New York, Oxford: Oxford University Press, 2007

[3] R. H. Stephenson. "Binary synthesis": Goethe's aesthetic intuittion in literature and science. Science in context 18(4), 553-581, 2005 doi:10.1017/S0269889705000669

[4] G. S. Halford, W. H. Wilson,, S. Phillips. Processing capacity defined by relational complexity: implications for comparative, developmental, and cognitive psychology. Behavioral and Brain Sciences 21(6), 803-831; discussion 831-864, 1998. doi:10.1017/S0140525X98001769
[5] G. S. Halford, R. Baker, J. E. McCredden, J. D. Bain. How many variables can humans process? Psychological Science 16, 70-76, 2005. doi:10.1111/j.0956-7976.2005.00782.x

[6] G. S. Halford, W. H. Wilson, S. Phillips. Relational knowledge: the foundation of higher cognition. Trends in Cognitive Sciences 14(11), 497-505, 2010. doi:10.1016/j.tics.2010.08.005

[7] J. Rohrhuber. Intuitions / Anschauungen. 02.07.2007 on WERTLOS-blog. Online available from http://www.wertlos.org/faits_divers/files/faits_divers_01.pdf

[8] G. Rizzolatti, L. Cattaneo, M. Fabbri-Destro, S. Rozzi. Cortical mechanisms underlying the organization of goal-directed actions and mirror neuron-based action understanding. Physiological Reviews 94(2), 655-706, 2014. doi: 10.1152/physrev.00009.2013

[9] Kraepelin, E. XI. Das manisch-depressive Irresein. in: Kraepelin E. Psychiatrie. vol. III. Leipzig: J.A. Barth. 1913. (pp.1183-1395), (engl.: www.biposuisse.ch/mixed.doc).

[10] G. R. S. Treviranus. A synopsis of cyclical biaxial (affective) models: from Kraepelin to Askland's genetics and evolutionary neuroanatomy. Poster. 11th International Review Bipolar Disorders, 2010, Rome. International Clinical Psychopharmacology 26, e48, 2011. doi:10.1097/01.yic.0000405714.06608.40 Online available at https://prezi.com/kosqybvz8aqx/

[11] E. Koutsoukos, E. Angelopoulos. Mood regulation in bipolar disorders viewed through the pendulum dynamics concept. International Journal of Bipolar Disorder 2(1), 9, 2014. doi:10.1186/s40345-014-0009-6

[12] G. Cui, S. B. Jun, X. Jin, M. D. Pham, S. S. Vogel, D. M. Lovinger, R. M. Costa. Concurrent activation of striatal direct and indirect pathways during action initiation. Nature 494(7436), 238-242, 2013. doi:10.1038/nature11846

[13] S. Axinn. The Logic of Hope: Extensions of Kant's view of Religion. Atlanta, GA: Rodopi: 141-156, 1994.

[14] Plato. The Republic. Transl. B. Jowett. J. Manis (Ed.). The Electronic Classics Series Hazleton, PA: PSU-Hazleton. Online available from http://worldlibrary.org

[15] R. M. Sorrentino, C. J. R. Roney. The uncertain mind: Individual differences in facing the unknown. Philadelphia: Psychology Press, 2000.

[16] R. M. Sorrentino, C. H. Andrew, X. C. Szeto, Z. Wang. Uncertainty regulation across cultures: An exploration of individual differences in Chinese and Canadian children in the classroom. Personality and Individual Differences, 54(3), 378-382, 2013.

[17] Westbrook, T. S. Braver. Dopamine does double duty in motivating cognitive effort. Neuron 89(4), 695-710, 2016. doi:10.1016/j.neuron.2015.12.029

[18] D. G. Tervo, M. Proskurin, M. Manakov, M. Kabra, A. Vollmer, K. Branson, A. Y. Karpova. Behavioral variability through stochastic choice and its gating by anterior cingulate cortex. Cell 159(1), 21-32, 2014. doi:10.1016/j.cell.2014.08.037.

[19] J. J. Gibson. The Theory of Affordances. In: R. Shaw, J. Bransford (eds.). Perceiving, Acting, and Knowing, edited by, 1977. ISBN 0-470-99014-7 
[20] C. Prévost, M. Pessiglione, E. Météreau, M. L., Dreher, J. C. Cléry-Melin. Separate valuation subsystems for delay and effort decision costs. Journal of Neuroscience 30(42), 14080-14090, 2010. doi:10.1523/JNEUROSCI.2752-10.2010

[21] A. E. Kelley, B. A. Baldo, W. E. Pratt. A proposed hypothalamic-thalamic-striatal axis for the integration of energy balance, arousal and food reward. Journal of Comparative Neurology 493, 72-85, 2005. doi:10.1002/cne.20769

[22] J. L. Haight, Z. L. Fuller, K. M. Fraser, S. B. Flagel. A food-predictive cue attributed with incentive salience engages subcortical afferents and efferents of the paraventricular nucleus of the thalamus. Neuroscience 340,135-152, 2017. doi:10.1016/j.neuroscience.2016.10.043

[23] G. J. Kirouac. Placing the paraventricular nucleus of the thalamus within the brain circuits that control behavior. Neuroscience, Biobehavioral Reviews. 56(1), 315-329, 2015. doi:10.1016/j.neubiorev.2015.08.005

[24] S. B. Flagel, T. E. Robinson, J. J. Clark, S. M. Clinton, S. J. Watson, P. Seeman, P. E. Phillips, H. Akil. An animal model of genetic vulnerability to behavioral disinhibition and responsiveness to reward-related cues: implications for addiction. Neuropsychopharmacology 35(2), 388-400, 2010. doi:10.1038/npp.2009.142

[25] S. B. Flagel, C. M. Cameron, K. N. Pickup, S.J. Watson, H. Akil, T. E. Robinson. A food predictive cue must be attributed with incentive salience for it to induce c-fos mRNA expression in cortico-striatal-thalamic brain regions. Neuroscience 196, 80-96, 2011.

doi:10.1016/j.neuroscience.2011.09.004

[26] J. L. Haight, K. M. Fraser, H. Akil, S. B. Flagel. Lesions of the paraventricular nucleus of the thalamus differentially affect sign- and goal-tracking conditioned responses. The European Journal of Neuroscience. 42, 2478-2488, 2015. doi:10.1111/ejn.13031

[27] K. K. Pitchers, S. B. Flagel, E. G. O'Donnell, L. C. Woods, M. Sarter, T. E. Robinson. Individual variation in the propensity to attribute incentive salience to a food cue: influence of sex. Behavioural Brain Research. 278, 462-469, 2015. doi:10.1016/j.bbr.2014.10.036

[28] T. A. Zielinski, G. P. Goodwin, G. S. Halford. Complexity of categorical syllogisms: An integration of two metrics. European Journal of Cognitive Psychology 22(3), 391-421, 2010. doi:10.1080/09541440902830509

[29] C. Boeckx, A. Benítez-Burraco. The shape of the human language-ready brain. Frontiers in Psychology 5, 282, 2014. doi:10.3389/fpsyg.2014.00282

[30] R. Cook, G. Bird, C. Catmur, C. Press, C. Heyes. Mirror neurons: from origin to function. Behavioral and Brain Sciences 37(2), 177-192, 2014. [Authors' response: 221-41]. doi:10.1017/S0140525X13000903

[31] V. Mohan, P. Morasso. Passive motion paradigm: an alternative to optimal control. Frontiers in Neurorobotics 5, 4, 2014. doi:10.3389/fnbot.2011.00004

[32] I. Kant. §43. On Art in general, 1790. In: I. Kant. Critique of Judgment. Trans. W. S. Pluhar. Indianapolis, Hackett, 1987.
[33] C. Di Dio, V. Gallese. Neuroaesthetics: A review. Current Opinion in Neurobiology 19(6), 682-687, 2009. doi:10.1016/j.conb.2009.09.001

[34] E. De Freitas, N. Sinclair. Mathematics and the body: Material entanglements in the classroom. (preface B. Rotman). Cambridge: Cambridge University Press, 2014.

[35] R. Pfeifer, J. C. Bongrad, D. Berry. Designing intelligence: Why brains aren't enough. Starmind. e-book, 2011. Online available from www.GRIN.com

[36] I. T. Kurniawan, M. Guitart-Masip, P. Dayan, R. J. Dolan. Effort and valuation in the brain: the effects of anticipation and execution. Journal of Neuroscience 33(14), 6160-6169, 2013. doi:10.1523/JNEUROSCI.4777-12.2013

[37] A.M. Ahrens, P. J. Meyer, L. M. Ferguson, T. E. Robinson, J. W. Aldridge. Neural activity in the ventral pallidum encodes variation in the incentive value of a reward cue. Journal of Neuroscience 36(30), 7957-7970, 2016. doi:10.1523/JNEUROSCI.0736-16.2016

[38] P. L. Croxson, M. E. Walton, J. X. O'Reilly, T. E. Behrens, M. F. Rushworth. Effort-based cost-benefit valuation and the human brain. Journal of Neuroscience 29(14), 4531-4541, 2009. doi:10.1523/JNEUROSCI.4515-08.2009

[39] A. Dager. Retuning brain circuitry to treat mental illness: the role of functional neuroimaging. Commentary for the Special Issue: Mechanisms of Change. Neuroimage pii: S1053-8119(17)30026-5, 2017.

[40] Y. S. Chung, D. Barch. Anhedonia is associated with reduced incentive cue related activation in the basal ganglia. Cognitve Affective Behavioral Neuroscience 15(4), 749-767, 2015. doi:10.10.3758/s13415-015-0366-3.

[41] L. H. Corbit, B. W. Balleine. Learning and Motivational Processes Contributing to Pavlovian-Instrumental Transfer and Their Neural Bases: Dopamine and Beyond. In: E. H. Simpson, P. D. Balsam (eds.). Behavioral Neuroscience of Motivation. Current Topics in Behavioral Neurosciences. Vol. 27. (pp 259-289). Springer Int., Cham ZG, 2016. doi:10.1007/7854_2015_388

[42] K. Askland, M. Parsons. Toward a biaxial model of "bipolar" affective disorders: spectrum phenotypes as the products of neuroelectrical and neurochemical alterations. Journal of Affective Disorders 94, (1-3), 15-33, 2006. doi:10.1016/j.jad.2006.02.024

[43] I. Hernádi, F. Grabenhorst, W. Schultz. Planning activity for internally generated reward goals in monkey amygdala neurons. Nature Neuroscience 18(3), 461-469, 2015. doi:10.1038/nn.3925

[44] R. G. Giaccio. The dual origin hypothesis: an evolutionary brain-behavior framework for analyzing psychiatric disorders. Neuroscience, Biobehavioral Reviews 30(4), 526-550 2006. doi:10.1016/j.neubiorev.2005.04.021

[45] M. Wolff, F. Alcaraz, A. R. Marchand, E. Coutureau. Functional heterogeneity of the limbic thalamus: From hippocampal to cortical functions. Neuroscience, Biobehavioral Reviews 54, 1, 120-130, 2015. doi:10.1016/j.neubiorev.2014.11.011

[46] S. N. Haber. Anatomy and Connectivity of the Reward Circuit. Chp. 1. In: J.-C. Dreher, L. Tremblay (eds.) Decision Neuroscience. An Integrative Perspective. 1st 10.1016/B978-0-12-805308-9.00001-4 
[47] S. N. Haber, B. Knutson. The reward circuit: linking primate anatomy and human imaging. Neuropsychopharmacology 35 , 4-26, 2010. doi:10.1038/npp.2009.129

[48] S. Ikemoto, C. Yang, A. Tan. Basal ganglia circuit loops, dopamine and motivation: A review and enquiry. Behavioural Brain Research 290, 17-31, 2015. doi:10.1016/j.bbr.2015.04.018

[49] M. A. Rossi, T. Sukharnikova, V.Y. Hayrapetyan, L. Yang, H. H. Yin. Operant self-stimulation of dopamine neurons in the substantia nigra. PLoS One 8(6), e65799, 2013. doi:10.1371/journal.pone.0065799

[50] C. F. Robles, A. W. Johnson. Disruptions in effort-based decision-making and consummatory behavior following antagonism of the dopamine D2 receptor. Behavioural Brain Research 320, 431-439, 2017. doi:10.1016/j.bbr.2016.10.043

[51] M. A. Hutchison, X. Gu, M. F. Adrover, M. R. Lee, T. S. Hnasko, V. A, Alvarez, W. Lu. Genetic inhibition of neurotransmission reveals role of glutamatergic input to dopamine neurons in high-effort behavior. Mol Psychiatry. 2017 Feb 14. doi:10.1038/mp.2017.7. [Epub ahead of print]

[52] C. E. Schwartz, P. S. Kunwar, D. N. Greve, L. R. Moran, J. C. Viner, J. M. Covino, J. Kagan, S. E. Stewart, N. C. Snidman, M. G. Vangel, S. R. Wallace. Structural differences in adult orbital and ventromedial prefrontal cortex predicted by infant temperament at 4 months of age. Archives of General Psychiatry 67(1), 78-84, 2010. doi:10.1001/archgenpsychiatry.2009.171

[53] G. E. Alexander, M. R. DeLong, P. L. Strick. Parallel organization of functionally segregated circuits linking basal ganglia and cortex. Annual Reviews of Neuroscience 9(0), 357-381, 1986. doi:10.1146/annurev.ne.09.030186.002041

[54] C. A. Hanlon, M. Canterberry, J. J. Taylor, W. DeVries, X. Li, T. R. Brown, M. S. George. Probing the frontostriatal loops involved in executive and limbic processing via interleaved TMS and functional MRI at two prefrontal locations: a pilot study. PLoS One. 8, e67917, 2013. doi:10.1371/journal.pone.0067917

[55] P. Krack, M. I. Hariz, C. Baunez, J. Guridi, J. A. Obeso. Deep brain stimulation: from neurology to psychiatry? Trends in Neuroscience 33(10), 474-484, 2010. doi:10.1016/j.tins.2010.07.002

[56] M. S. Mega, J. L. Cummings. Frontal-subcortical circuits and neuropsychiatric disorders. Journal of Neuropsychiatry and Clinical Neurosciences 6(4), 358-70, 1994. doi:10.1176/jnp.6.4.358

[57] R. M. Bonelli, J. L. Cummings. Frontal-subcortical circuitry and behavior. Dialogues in Clinical Neuroscience 9(2), 141-151, 2007.

[58] E. V. Demos (ed.). Exploring Affect. The Selected Writings of Silvan S. Tomkins. Cambridge UK: Cambridge University Press \& Paris: Éditions de la Maison des Sciences de l'Homme. p. 53, 86, 88.

[59] L. Q. Uddin, J. Kinnison, L. Pessoa, M. L. Anderson. Beyond the tripartite cognition-emotion-interoception model of the human insular cortex. Journal of Cognitive Neuroscience 26(1), 16-27, 2014. doi:10.1162/jocn_a_00462

[60] G. R. S. Treviranus. My delight is your torment. Extending the Aristotelian syllogistic "dyn4"-generator of natural language terms to 64 relations. Proceedings WPA Thematic
Conference on Intersectional Collaboration (Oct. 30 - Nov. 2 , 2014), Athens. Bologna: Medimond, 2015.

[61] E. C. Nook, J. L. Schleider, L. H. Somerville. A linguistic signature of psychological distancing in emotion regulation. Journal of Experimental Psychology: General. 2017. doi:10.1037/xge0000263. [Epub ahead of print]

[62] N. Enkhjargal, J. Matsumoto, C. Chinzorig, A. Berthoz, T. Ono, H. Nishijo. Rat thalamic neurons encode complex combinations of heading and movement directions and the trajectory route during translocation with sensory conflict. Frontiers in Behavioral Neuroscience 8, 242, 2014 doi:10.3389/fnbeh.2014.00242

[63] S. M. Sherman, R. W. Guillery. Distinct functions for direct and transthalamic corticocortical connections. Journal of Neurophysiology 106, 1068-1077, 2011 doi:0.1152/jn.00429.2011

[64] M. Johnson, G. Ojemann. The role of the human thalamus in language and memory: evidence from electrophysiological studies. Brain and Cognition 42, 218-230, 2000.

[65] B. Crosson. Thalamic mechanisms in language: a reconsideration based on recent findings and concepts. Brain and Language 126(1), 73-88, 2012.

doi:10.1016/j.bandl.2012.06.011

[66] M. Wahl, F., Friederici, A. D. Marzinzik, A. Hahne, A. Kupsch, G. H. Schneider, D. Saddy, G. Curio, F. Klostermann. The human thalamus processes syntactic and semantic language violations. Neuron 59(5), 695-707, 2008. doi:10.1016/j.neuron.2008.07.011

[67] F. Klostermann, L. K. Krugel, F. Ehlen. Functional roles of the thalamus for language capacities. Frontiers in Systems Neuroscience 7, 32, 2013 doi:10.3389/fnsys.2013.00032

[68] D. Wiechmann. Understanding complex constructions: A quantitative corpus- linguistic approach to the processing of english relative clauses. Doctoral thesis in philosophy. Friedrich-Schiller-Universität Jena, 2010. http://d-nb.info/1006930604

[69] A. S. Mitchell, S. M. Sherman, M. A. Sommer, R. G. Mair, R. P. Vertes, Y. Chudasama. Advances in understanding mechanisms of thalamic relays in cognition and behavior. Journal of Neuroscience 34(46), 15340-15346, 2014. doi:10.1523/JNEUROSCI.3289-14.2014

[70] A. A. Ford, W. Triplett, A. Sudhyadhom, J. Gullett, K. McGregor, D. B. Fitzgerald, T. Mareci, K. White, B. Crosson. Broca's area and its striatal and thalamic connections: a diffusion-MRI tractography study. Frontiers in Neuroanatomy 7, 8, 2013. doi:10.3389/fnana.2013.00008

[71] H. Barbas, M. Á. García-Cabezas, B. Zikopoulos. Frontal-thalamic circuits associated with language. Brain and Language 126(1), 49-61, 2013. doi:10.1016/j.bandl.2012.10. 001

[72] J. J. Stott, A. D. Redish. A functional difference in information processing between orbitofrontal cortex and ventral striatum during decision-making behaviour. Philosophical Transactions of The Royal Society B Biological Sciences 369(1655), 2014.

doi:10.1098/rstb.2013.0472

[73] N. K. Cooch, T. A. Stalnaker, H. M. Wied, S. Bali-Chaudhary, M. A. McDannald, T. L. Liu, G. Schoenbaum. Orbitofrontal 
lesions eliminate signalling of biological significance in cue-responsive ventral striatal neurons. Nature Communications 6, 7195, 2015. doi: 10.1038/ncomms8195

[74] D. Talmi, R. Atkinson, W. El-Deredy. The feedback-related negativity signals salience prediction errors, not reward prediction errors. Journal of Neuroscience 33(19), 8264-8269, 2013. doi:10.1523/JNEUROSCI.5695-12.2013

[75] A. M. Ahrens, B. F. Singer, C. J. Fitzpatrick, J. D. Morrow, T. E. Robinson. Rats that sign-track are resistant to Pavlovian but not instrumental extinction. Behavioral Brain Research 296:418-430, 2016 doi:10.1016/j.bbr.2015.07.055

[76] J. Du Hoffmann, S. M. Nicola. Activation of dopamine receptors in the nucleus accumbens promotes sucrose-reinforced cued approach behavior. Frontiers in Behavioral Neuroscience, 10, 144, 2016. doi:10.3389/fnbeh.2016.00144

[77] S. E. Morrison, M. A. Bamkole, S. M. Nicola. Sign tracking, but not goal tracking, is resistant to outcome devaluation. Frontiers in Neuroscience 9, 468, 2015. doi:10.3389/fnins. 2015.00468

[78] H. M. Nasser, Y. W. Chen, K. Fiscella, D. J. Calu. Individual variability in behavioral flexibility predicts sign-tracking tendency. Frontiers in Behavioral Neuroscience 9, 289, 2015. doi:10.3389/fnbeh.2015.0028

[79] J. M. Richard, D. C. Castro, A. G. Difeliceantonio, M. J. Robinson, K. C. Berridge. Mapping brain circuits of reward and motivation: in the footsteps of Ann Kelley. Neuroscience, Biobehavioral Reviews 37(9 PtA), 1919-1931, 2013. doi:10.1016/j.neubiorev.2012.12.008

[80] S. B. Flagel, S. J. Watson, T. E. Robinson, H. Akil. Individual

i Abbreviation codes:

1. Neuroanatomy, Neurochemistry: ACC Anterior cingulate cortex aINS Anterior insula; CSTC:Cortico-striato-thalamo-cortical circuits; HA Histamine; MC Mast cell; Nac Nucleus accumbens; OFC Orbitofrontal cortex; PVT paraventricular nucleus of thalamus; vmPFC ventromedial Pre-Frontal Cortex.

2. Psychology / Ethology: UOs Uncertainty-Oriented Individuals (Richard M. Sorrentino); COs Certainty-Oriented Individuals (Richard M. Sorrentino); UO-versus-CO Uncertainty versus Certainty "orientation"; MBL Model-based learning; MFL Model-free learning; GTs goal-trackers; GT goal-tracking; STs sign-trackers; ST sign-tracking.

3. Neuro-Economics: Effme maximal expendable effort; RPE Reward Prediction Error; PE( $-\Delta \% \mathbf{E f f m e})$ RPE normalized to the maximum expendable effort.

4. dyn4-TAM modeling. dyn4TAM modified classic mixed bipolar disorder model; $\mathbf{T} \sim, 4 D \mathbf{T}$ symbolic 4-dimensional cognitive processing; $4 D$-Thought symbolic 4-dimensional cognitive processing; $\mathbf{A} \sim, 5+D \mathbf{A}$ intuitive 5- or higher-dimensional cognitive processing; $5+D$-Action intuitive 5- or higher-dimensional cognitive processing; Mood dichotomic negative or positive valence; $\mathbf{M} \sim$ dichotomic negative or positive valence; $\mathrm{T} / \mathrm{t}, \mathrm{A} / \mathrm{a}, \mathrm{M} / \mathrm{m}$ dichotomic realizations of $\mathrm{T}, \mathrm{A}$, and $\mathrm{M}$ in triples. $\mathbf{P}\{\mathrm{A} \rightarrow \mathrm{T}\}$ Perception, i.e. transitions from 5+-Action to $4 D$-Thought; $\mathbf{I}\{\mathrm{T} \rightarrow \mathrm{A}$ Intention, i.e. transitions from 4D-Thought to 5+-Action; AW, AWs Appropriation Wave, Appropriation Waves; SHO Simple Harmonic Ooscillator; Need-t $\sim \mathrm{a} \sim \mathrm{m} \sim$ Need with low Thought, Action, and Mood; Worry-T a $\sim \mathrm{m} \sim$ Worry with much Thought, low Action and Mood; Fear-t $\sim \mathrm{A} \sim \mathrm{m} \sim$ Fear with much Action, low Thought and Mood; Bliss-t $\sim \mathrm{a} \sim \mathrm{M} \sim$ Bliss with elated Mood, low Thought and Action; Pursuit-T A $\sim \mathrm{M} \sim$ Pursuit with much Thought, Action, and Mood Joy-t $\sim \mathrm{A} \sim \mathrm{M} \sim$ Joy with low Thought, much Action and Mood; Interest-T $\sim \mathrm{a} \sim \mathrm{M} \sim$ Interest with low Action, much Thought and Mood; Despair-T A $\sim \mathrm{m} \sim$ Despair with low Mood, much Thought and Action.

5. Logic: SquOpp Square of Oppositions (Aristotle); $\forall, \neg \forall$ True for all, not for all; $\exists, \neg \exists$ True for at least one, for none; $\neg$ Negation. differences in the propensity to approach signals vs. goals promote different adaptations in the dopamine system of rats. Psychopharmacology (Berl) 191(3), 599-607, 2007. doi:10.1007/s00213-006-0535-8

[81] S. E. Chang, K. S. Smith. An omission procedure reorganizes the microstructure of sign-tracking while preserving incentive salience. Learning \& Memory. 23(4), 151-155, 2016. doi:10.1101/lm.041574.115

[82] S. D. Fisher, J. P. Gray, M. J. Black, J. R. Davies, J. G. Bednark, P. Redgrave, E. A. Franz, W. C. Abraham, J. N. Reynolds. A behavioral task for investigating action discovery, selection and switching: comparison between types of reinforcer. Frontiers in Behavioral Neuroscience 8, 398, 2014. doi:10.3389/fnbeh.2014.00398

[83] T. C. Blanchard, B. Y. Hayden, E. S. Bromberg-Martin. Orbitofrontal cortex uses distinct codes for different choice attributes in decisions motivated by curiosity. Neuron 85(3), 602-614, 2015. doi:10.1016/j.neuron.2014.12.050

[84] S. B. Flagel, H. Akil, T. E. Robinson. Individual differences in the attribution of incentive salience to reward-related cues: Implications for addiction. Neuropharmacology 56 (Suppl 1), 139-148, 2009. doi:10.1016/j.neuropharm.2008.06.027

[85] C. L. Barberini, S. E. Morrison, A. Saez, B. Lau, C. D. Salzman. Complexity and competition in appetitive and aversive neural circuits. Frontiers in Neuroscience 6, 170, 2012. doi: $10.3389 /$ fnins. 2012.00170

[86] G. R. S. Treviranus. For Value or for Worth? Part 2: A Neuroeconomical Thought-Action-Mood- Space modulated by (Un-)Certainty as Sign- or Goal-Tracking. Universal Journal of Psychology, 5(2), 50-65, 2017. 